\title{
PHOTOVOICE AS A NARRATIVE TOOL FOR DECOLONIZATION: BLACK WOMEN AND LGBT STUDENT EXPERIENCES AT UCT
}

\author{
S. Kessi \\ Department of Psychology \\ University of Cape Town \\ Rondebosch, South Africa \\ e-mail: shose.kessi@uct.ac.za
}

\section{ABSTRACT}

Decolonization is a key term in the current higher education crisis across South African universities as student movements are advocating for free decolonized education. In this article, I explore how Photovoice research, as a narrative approach combined with participatory action methods, can engage a group of black, working-class, and lesbian, gay, bisexual, and transgender (LGBT) students at the University of Cape Town (UCT) to explore their daily experiences on campus in relation to the call for decolonization. Findings demonstrate how naming decolonization allows students to locate their own experiences within a context of power relations and expose alienating institutional legacies. Of particular relevance are the experiences of students of diverse gendered identities whose daily struggles are often rendered invisible through multiple bureaucratic and cultural assumptions. Students spoke about the violence of institutional spaces, the policing of their bodies and the silencing of alternative ways of knowing and doing.

Keywords: Photovoice, students, race, gender, higher education, decolonization

\section{INTRODUCTION}

Decolonization is becoming a popular term in the current higher education crisis across South African universities as student movements are advocating for free decolonized education. This call for decolonization is not limited to the university alone but is about South African society as a whole and its location in a global environment. Access to university implies access to skills, networks and knowledge. In the context of the modern university, this means developing an understanding of and gaining access to a system of global civilization, which has coloniality at its basis (Maldonado-Torres 2016). Fundamentally therefore, the university is a site of struggle, a battle for knowledge and power, dignity and recognition. My primary concern in this article is to examine the experiences of a group of black ${ }^{1}$ students of diverse gendered identities who discuss their daily experiences at the University of Cape Town (UCT) and their views on decolonization. These combined aims of the article are useful in locating students' experiences within a broader socio-historical framework of which the University represents one site where these battles for knowledge, power, dignity and recognition are played out. 
There is much excitement and anxiety around the current student movements for decolonization. Transformation in higher education has been largely confined to demographic change focusing on employment equity policies with the view of redressing apartheid inequalities, particularly in historically white institutions. Affirmative action policies have, in many cases, led to an increase in the diversity of student bodies, in terms of both race and gender (Cloete 2002). The decolonial turn, however, is calling for an approach better suited to address the complexities of apartheid and colonial legacies. At stake is changing attitudes, mindsets, institutional systems, and structural changes at micro and macro levels. This requires a fundamental shift in the organization of knowledge and the organization of society (Said 1993).

In many universities, deeply entrenched patterns of institutional behavior remain racialised, hetero-patriarchal, middle-class, and Euro-American (Sennett et al. 2003; Walker 2005; Woods 2001) causing those who fall outside of certain categories to question their belonging within them (Read, Archer and Leathwood 2003). Consequently, the lived experiences of many students in higher education institutions do not reflect the positive gains anticipated by the transition to democracy as many experience the university environment as alienating (Cornell and Kessi 2016; Kessi and Cornell 2015; Soudien et al. 2008). Student protests across South Africa and internationally are indicative of the need for change and for creating spaces of belonging. The narrative of black pain by student activists highlights the everyday struggles of racism on campuses across the country (Ndebele 2016). These experiences refer to interpersonal interactions with others, systemic processes that exclude such as financial and academic exclusions, and their relationship to knowledge acquisition in a predominantly western-oriented curriculum.

Of particular importance in this article are the experiences of black women students and black students of non-conforming gendered identities and sexual orientations. This focus is not only important for highlighting the discrimination that occurs in university establishments but also to foreground experiences that are often sidelined in resistance movements in higher education (Matandela 2015). Black feminists have described the erasure of women and lesbian, gay, bisexual, and transgender (LGBT) groups from histories of black revolutionary thought (Davies 2014; Mwikya 2014).

In South Africa, despite the adoption of a progressive democratic constitution in 1996 in terms of gender rights and same-sex relationships (Matebeni 2015), access to economic and political power remains skewed and levels of gender-based violence remain reportedly high (Boonzaier 2014; Mkhize et al. 2010). Stigmatising images of LGBT individuals in particular as unnatural, morally flawed and criminal are commonplace (Matebeni 2015) and historically rooted in imperial white hetero-patriarchal structures (Alexander 2005). The intersection of 
racial and sexual regulation cannot be divorced from colonial and apartheid histories, as was enshrined in the Immorality Act of 1927 (Ratele 2009). These experiences are reflected in university spaces where women and LGBT students are often at the receiving end of exclusionary practices and where their specific needs are not catered for (Hames 2007; McKinney 2005; Msibi 2013). The narratives of black women and LGBT students thus provide a lens through which the intersections between race, gender, and sexual identities produce a more complex and intersecting understanding on which a decolonial agenda can be premised.

\section{EVERYDAY NARRATIVES OF UNIVERSITY LIFE}

Examining the politics of everyday life reveal how people find ways of negotiating their identities, developing a sense of belonging and difference, and forming communities and social movements (Howarth and Andreouli 2017). Addressing institutional racism through demographic change alone says little about the intricate ways in which it operates in the everyday and the seemingly ordinary practices that need to change. Understanding the history, culture, and social context of an institution through the lens of everyday conversations, interactions, and affective experiences often reveals the micro and macro changes that need to take place, in other words, both the institutional practices as well as the values, beliefs, and principles that guide them.

The importance of narrative research, especially in a participatory framework, is that it asks participants to not only reflect on their individual experiences, but to connect with others in a similar situation thus forging a network of support and community ties (Kessi and Boonzaier 2017). Narrative research engages participants to understand their everyday reality in relation to a broader institutional and societal context and the categories of power and subordination that guide them (Riessman 2008). Creating a narrative is an emancipatory process (Murray 2000) because it provides coherence and recognition to someone's experience. When combined with PAR, it enables participants to act on their newly found agency through collective initiatives aimed at social change and social justice (Brydon-Miller 1997). In this case, the combined narrative and PAR approach was effective in unlocking the subjectivity and power of participants to counter experiences of exclusion and build understandings and strategies for change.

\section{PHOTOVOICE METHODS}

Photovoice methods involve the production of photographs and written stories (photonarratives) by participants to document their lives and experiences in a particular context (Wang and Burris 1997). Participants are given cameras and through a guided facilitation process are asked to take photographs that illustrate the assets and challenges that exist in their community, 
how their lives are affected by these, what needs to change and how. Photovoice is about engaging participants in social activities that can disrupt relations of power and lead to positive changes in their communities.

Participants in this project included 13 black, female, working class, and LGBT students from undergraduate and postgraduate programmes and a range of departments and faculties at UCT, including Commerce, Engineering, and the Humanities. All students self-identified as black and some students declared their gendered identities although they were not required to do so. These self-descriptions included: cisgender woman, non-binary trans person and lesbian, gay man, trans woman, gender nomad, and female to male transgender. These participants constitute only one group of students who formed part of a larger study on black students' experiences at UCT that spanned three years (2013-2015) in which a total of 36 students participated. Over a period of approximately six months in 2015, the participants in this phase of the project partook in a series of activities:

- $\quad$ One recorded focus group discussion about the meaning of decolonization. Participants were divided into two groups of seven and six respectively.

- A photography workshop where they learnt technical skills from a professional photographer, such as lighting, framing, and composition as well as issues regarding the ethics of taking photographs especially when involving secondary participants. The workshop was combined with a group discussion with the researchers about students' experiences on campus and how to convey these through photographs and written stories. The themes emerging from the initial focus group were used to guide this session in order to assist participants in locating their experiences within a broader institutional and historical environment.

- Following the workshop, participants were given cameras for a two-week period during which they produced their photo-narratives. They were advised to produce between three and five photographs with accompanying stories that would be displayed at the photography exhibition. These guidelines were not strictly adhered to but were set to take into account the budgetary constraints of printing and framing the photo-narratives.

- A feedback session was held during which participants shared their photo-narratives amongst each other and invited students and academics. The aim of the feedback session was to get participants accustomed to presenting their experiences to a wider audience prior to the exhibition and to receive feedback and critical engagement on their ideas. Some participants decided to modify their stories thereafter. During this session, participants also made decisions about the exhibition, it's location and display; an 
invitation list was agreed upon for the opening event.

- Finally, a public exhibition of their photo-narratives took place on upper campus in November 2015. The exhibition lasted three weeks and was held in one of the busiest buildings on upper campus, notably Beattie Building where faculty office is housed. The Dean of the Humanities Faculty opened the exhibition and participants and supporting staff members also made public statements at the opening event.

Altogether, participants met four times in the formal aspects of the projects. These different stages of the process were instrumental in assisting participants to reflect on their individual and shared identities, to collectively share their experiences of belonging and exclusion, to develop historical or causal explanations to their lived experiences, and to understand the possibilities and limitations of enacting change.

The findings from the project are presented below through a thematic analysis of data extracted from the focus groups, photo-narratives, as well as reflections on the Photovoice process itself. The findings are reported on in the same sequence as the various stages of the project to illustrate the building blocks in the development of narratives through the Photovoice approach. The discussion - reflection - action cycle that is typical of Photovoice projects (Catalani and Minkler 2010) can assist participants in making sense of their experiences and instill a desire for social action and social justice.

\section{ANALYSIS AND DISCUSSION}

Three themes emerging from the data are discussed in this analysis section. The first theme, transformation versus decolonization, critically assesses the shift in the discourse from transformation to decolonization in higher education and how students make sense of this shift in relation to their day-to-day experiences on campus. The second theme, home away from home, speaks to participants' daily realities of exclusion on campus and how these are reflected in institutional practices and analysed in relation to the context of knowledge hierarchies in higher education. The third theme, solidarity, resistance, and change describes the ways in which black and LGBT students are not passive agents within the university but actively resist, challenge and disrupt on a daily basis the institutional and intergroup relations of power though a variety of activities and interventions.

\section{TRANSFORMATION VERSUS DECOLONIZATION}

Before the Rhodes Must Fall movement (RMF) ${ }^{2}$ that emerged at UCT in 2015, policies aimed at bringing about change in the institution were framed around a narrative of transformation. ${ }^{3}$ Students in the project described the emphasis on transformation in institutions as a policy 
framework that conceals the underlying problems of inequality and discrimination. The concept was described as elusive, technocratic and largely based on demographic change:

"Um, transformation, well to me that word is very problematic ... you know, the whole transformation, gender and equity in parliament and they just take any Tom, Dick and Harry from the street, put them there, and 'we've transformed!'. Put a woman in the place, and when you check the credentials, that woman doesn't even qualify to be there, she's just to cover the quota, or to, to, just to get somebody who's going to be silenced on issues, uh, you don't know anything about this particular issue.” (Tumi).

"Transformation has a window dressing element to it. Transformation is that thing you try to quantify on paper, so we can say, 'pre-1994 we were like this' or 'post-1994, the 2000s or whatever year we are dealing with, we are like this now', and noting the disparities between that. So, ja, transformation always feels like something where we are just quantifying things just to determine numbers.” (Samkelo).

"I think transformation is, it's sort of, it's forward looking, in the way it's like, currently being conceptualised, it doesn't look at you and really engage with your opinion but it promises, it like sort of promises you, like this, you know, um, sort of like, heavenly world that might come if you just hang in there (Tumi: exactly!) So, transformation is not, for me I also reject it politically.” (Thandi).

Tumi, Samkelo, and Thandi describe transformation as a term devoid of real content and one that is oblivious of the day-to-day experiences of people on campus. By not naming the issues that need to be transformed, the term itself falls into the trap of concealing relations of power in the institution. It raises questions of identity in a technocratic fashion wherein the focus on race and gender is framed purely in terms of demographic change that can have contradictory effects. When Tumi says: “that woman doesn’t even qualify to be there, she’s just to cover the quota” or Samkelo, who refers to transformation as "window dressing”, they are highlighting how certain agendas can be hijacked through poorly implemented affirmative action policies. A common criticism of affirmative action in higher education is one of lowering standards (Kessi and Cornell 2015; Gordon 2015) where it is deemed that black students entering with lower matric scores get preference over university places and are taking the place of others (Jones 2012). This is a perspective that denies the imbalances of a societal structure where the majority of black students come from under-resourced schools, thus their matric results are a poor reflection of their intellectual capabilities. It is also one that fails to take into account the systemic issues that permeate institutions that cannot be resolved from simply replacing white with black. As Thandi suggests, transformation in such a context is an empty promise.

By contrast, decolonization brings to the fore issues of power, knowledge and identity. It is a term that immediately frames the historical context of colonization as a point of reference in terms of what needs to change. 
"When you decolonise you have to deconstruct certain systems of power." (Tumi).

"Whereas something like decolonisation, that, that, the element of decolonisation in terms of like the psychological effects that it had we still hold onto today, is still entrenched in us today. I feel like that act inherently you cannot quantify. Decolonisation, it's something that we experience, it's something that you need to experience each other in trying to break down, and I think it has way more meaning in it and is a much powerful means of going about it rather than just saying, 'We're transforming'.” (Samkelo).

“Um, decolonisation has allowed, um, sort of me, like, I'm a bastard of the system, like the system does not give a shit about me, people do not give a shit about me. So, decolonisation has sort of, now I know where to like source the pain, like I found sort of like, so this is not some sort of random occurrence. It was well organised, there were conferences and it was orchestrated. And, and that has also somehow empowered me like beyond what transformation did ... like pre-RMF, I struggled very much in terms of my identity and it's the decolonisation theory, that kind of like, reconcile, like, how I experience the world and like how I feel.” (Thandi).

These references to decolonization in students' testimonies emphasize the role of experience and how experience is a reflection of a historical context. The shift from transformation to decolonization in the discourse of RMF and subsequent student protests allowed students to identify with and locate themselves in a way that made sense to them: "that also somehow empowered me like beyond what transformation did”. For black students who find themselves in a historically white university, decolonization allows them to start reflecting on and name the "source of the pain" and the "psychological effects" of a system that misrecognizes them. Decolonisation gave meaning to their identities as outsiders and enabled them to start constructing coherent narratives about themselves. As Thengi says:

"It's like the powers that be are always convincing us that we always need to be in this state of eternal gratefulness, being able to exist in their space .... So, it's always like a, 'once upon a time you weren't able to be here, and put your head down and exist how they want you to exist, and come out and get a good job’.”

Thengi is referring here to the dominant culture and mindset of an institution where certain bodies were never "meant to be". The expectation of having to be grateful to be at UCT despite the adversity of everyday interaction is contradictory to the development of positive identities. Evidence of low self-esteem and diminished academic performance in such environments has been documented elsewhere (Kessi and Cornell 2015; Woods 2001). Thengi also refers to the difficulties in seeing oneself beyond the frame of discourse based purely on racial demographics. In such a context, black students will remain eternal outsiders to a system that undervalues their identities, knowledges, and capabilities.

These reflections on the idea of a decolonial framework for transformation formed the basis on which the project then sought to unpack the very real and everyday experiences that gave content to what is meant by decolonization. 


\section{HOME AWAY FROM HOME?}

Students’ narratives of daily life at UCT were fraught with unfulfilled expectations. Many arrived at university expecting to find a space where they would be accepted for who they were and find a home away from home. Being located in Cape Town, UCT came with promises for students like Sipho who identified as gay:

"Um, yeah it was more like, it's, Cape Town is more liberal in terms of, um, compared to where I'm from, from home, ikasi and everything. It's much more liberal compared to home. At home, obviously a gay person cannot just walk by, and you won't have the guys call you names, 'stabane' or 'Simangumangu', or 'do you have a penis or a vagina?'."

Samkelo, coming from a girl's high school also had expectations of the university environment as one of openness and acceptance for people of various gendered identities. However, Samkelo who identifies as a non-binary transgender student ended up once more in an all-female residence at UCT called Graca Machel, where students are nicknamed “first ladies” given Mrs Machel's relationship to the late President, Nelson Mandela. In the following photo-narrative, Samkelo describes this experience:

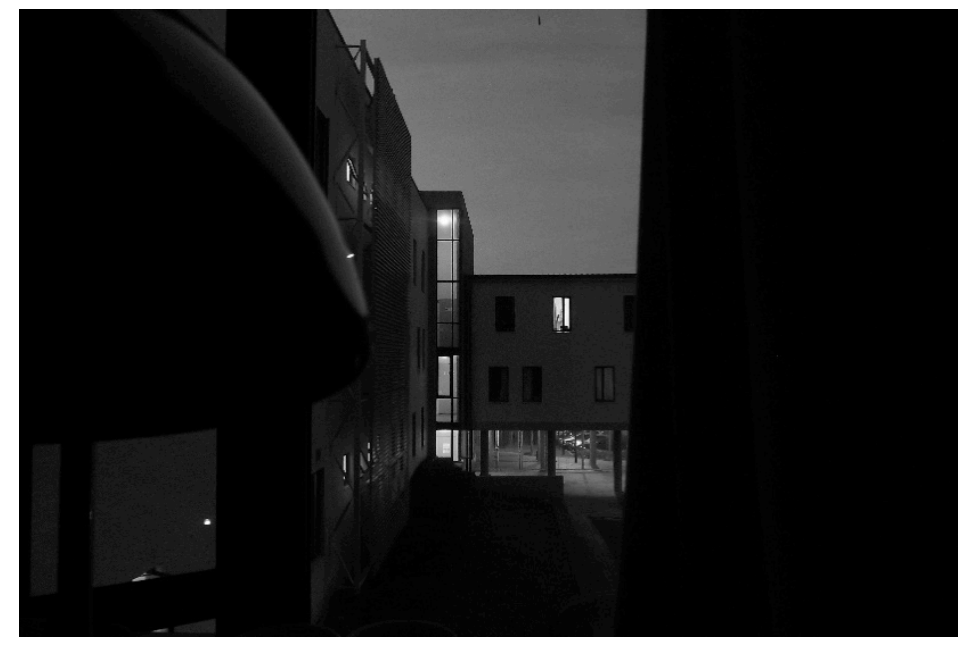

Photo 1: Home?

“My ID tells lies about who I am; I'm subhuman so I don't deserve a restroom; the language to accommodate me does not exist in the vocab of the majority.

And even when I come home, this space expects me to be a 'first lady'.

Home should not be violent.

There's no space in which I am acknowledged and validated. There are only spaces that tell me who I am.” 
Similarly, Thandi, a black working-class male to female transgender student was assigned to an all-male residence upon arrival. In her story called Isolation, annihilation and Trans Pain, she says:

“... My journey of transitioning began while I stayed in a 300+ strong male residence. UCT male residence cultures cater for the white cisgender heterosexual middle class able-bodied male .... All I can remember about Kopano is the sheer amount of isolation and annihilation I felt. Sure, I had a few friends here and there but the majority of the residence would ignore my existence. Now that I look back on this experience after acquiring the language to describe my experience, I have come to understand that my body at the time was subjected to unprecedented levels of violence: trans misogynoir, sexism, transphobia, homophobia etc. all resulting from the deeply imbedded patriarchy in the residence system.”

Both Samkelo and Thandi describe these experiences as isolating and violent. The invisibilisation of transgender identities are daily affective occurrences that have a significant impact on students' sense of self and sense of belonging to UCT. Students describe the difficulties in naming what they go through given the limitations of language to describe and make sense of their experiences. Whilst Samkelo speaks of the dehumanization of being referred to as a "first lady", Thandi explains how she had to learn a new language that enabled her to understand her own positionality in a white, cisgender, heterosexual, middle-class, ablebodied, male environment. Experiences of university residences have been documented as particularly alienating for transgender students (Hames 2007; Msibi and Jagessar 2015; Rankin 2003), this in light of the dominant culture of cisgenderism (Seelman 2014).

This invisibility and misrecognition transpires in a number of ways across the institution. Fiki, a female to male trans student, alludes to this in his photo-narrative below:

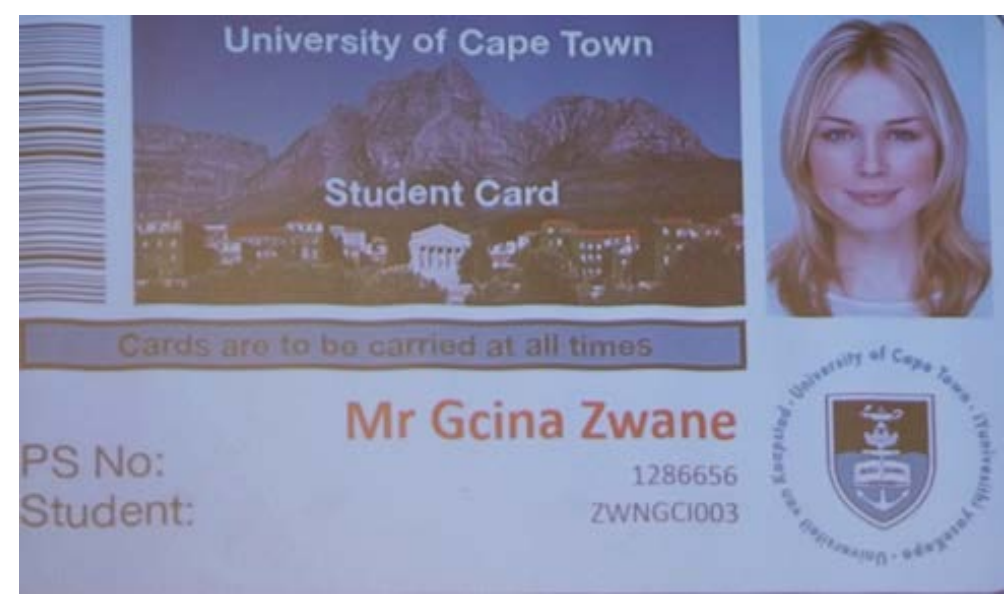

Photo 2: Harassment for access - the UCT student card 
"The picture was taken in a classroom setting. It speaks to the heteronormative and cisgendernormative (cis-het) teaching and administration practices at UCT which erase, victimise and silence all students with transgender experiences. The student card was created to bring about the daily conflict experienced by transgender students at UCT.

This being the card one has to produce to access almost all UCT facilities for example; the Jammie shuttle, UCT libraries, UCT residence. For transgender students, it also stands for violence, body policing and harassment. I deliberately created a contrast of the student card holder and her credentials since the probability of meeting a blonde white woman called Mr Gcina Zwane is zero to none. However, this discrepancy captures the daily reality of many transgender students. Society expects them to assimilate to gender norms that are consistent with their 'assigned gender', and to forget about being their true selves. A white being cannot possibly be a Mr Gcina Zwane; in the same light, a trans woman/man cannot be a Mr/Miss respectively.”

The student identity card is symbolic of how trans identities have to navigate multiple experiences of alienation on a daily basis and the overwhelming pressure to assimilate to a rigid institutional culture. It describes the symbolic and structural violence of the cis-gendered spaces cutting across higher education institutions (Bilodeau 2009; Garvey and Rankin 2015; Seelman 2014) including restrooms, classrooms, the Jammie shuttle and the library. These are spaces that students frequent regularly and in which their identities as transgender are repeatedly hidden or denied and their experiences often go unnoticed, concealed in bureaucratic policies and procedures. The reference to a white woman in this narrative also foregrounds the complexity of the black experience as intersecting with gendered oppressions (Crenshaw 1994; Collins 2000).

These narratives of everyday experiences can reveal the less hidden ways in which the legacies of the past still dominate our institutions in very real and palatable ways. Of particular significance is the residence space in itself as one that is framed as representing a home for many students but one that simultaneously halts the development of identity and self-esteem. For example, Samkelo’s journey to make sense of their identity in such a context is a painful account of self-rejection:

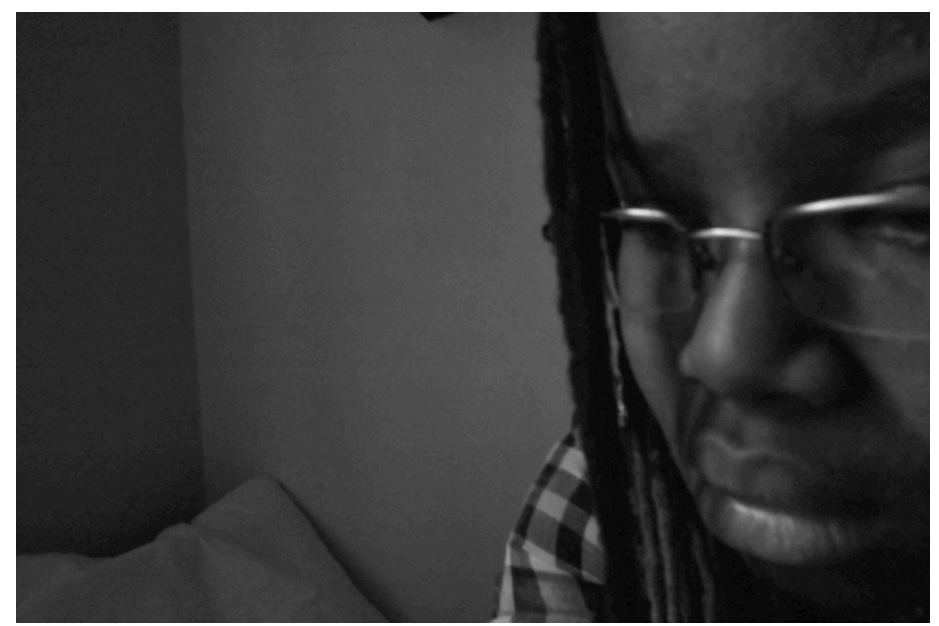

Photo 3: How do I escape violence when it's in the mirror? 
"I have successfully avoided seeing 'myself' for years. Rarely do I take selfies or look at reflections in windows or mirrors - I even brush my teeth in the shower to avoid that brief moment in the bathroom.

In rare moments of bravery (or self-torment - the jury is out) I've stood and glared in a mirror and watched the agony of repressed pain swell up; I've watched tears well up and slide down her cheeks ... and felt the moisture run down my cheeks.

Trans* is a complex existence: the cognitive dissonance of knowing how you look like yet refusing to accept it as 'you' whilst simultaneously not hating your physicality. Because even through that face you can still see the beauty in that face.”

The process of becoming is never devoid of the social context in which one finds oneself. Just as there is an individual element to one's identity, it is also created in and through our relationship with others and how we are seen by others (Hall 1990). In the absence of the social and symbolic resources available to develop a positive identity, individuals internalize images of themselves in ways that lead to self-negation (Fanon 1986).

These experiences are also a reflection of the need for an epistemic rupture (NdlovuGatsheni 2013). When students recognise themselves in the decolonization narrative, it is because the policing of their bodies on a daily basis is a reflection of the continued control of gender and sexuality (Alexander 2005) that is closely linked to the control of subjectivity and knowledge rooted in colonial epistemologies (Ndlovu-Gatsheni 2013). Just as the black/African body has been historically dehumanized and crudely sexualized in academic and popular discourses (Lewis 2011; Mwikya 2014), violence against black women can be traced to the violent and male-dominated civilizing mission of the colonial encounter (Mama 1997). Race, gender, class, and sexual segregation and oppression are closely tied up in colonial and apartheid practices of control and subjugation (Ratele 2009).

Such a context also creates the conditions for horizontal forms of violence (Freire 1970) between the oppressed themselves. As Fiki explains:

"So, so for me a transformed UCT would be waking up at home, getting into a Jammie, getting off at Upper Campus, maybe going to the library, going to the toilet without anybody policing my genitals. Like, people here, I mean the system has created such a structure that black people will assert violence on other black people. So, you have CPS walking around, security, in coats policing each and every other body that doesn't fit the spectrum, and in such a way that, I get this question every day, 'Are you male or female?' So, always in my mind I think, 'What makes you think I'm female? What makes you think I'm male? So, in your head are you seriously trying to figure out what's happening between my legs?' And, and it's such a violent space to be in (...) So, it's a very, um [pauses] difficult space to be in. UCT, uh, first university in Africa, whatnot, top, and you are walking around as a student in this university and every single day you need to explain yourself.” 
In his account, Fiki describes the policing of his body by black security officers from Campus Protection Services (CPS). In doing so, he links racial, classed, and gendered oppressions - a working class black man exerting control over a black transgender postgraduate student. One possible explanation is what Fanon refers to as the racial distribution of guilt (see Hook 2004) - when the oppressed, rather than taking responsibility for their own oppressions, tend to employ violence towards others to reassert their dominance. This reflects the legacies of a system dependent on hierarchies of differences and oppressions (Crenshaw 1994; Collins 2000).

The limits of language to define and make sense of the identities of black, working class and LGBT students exposes a knowledge system that has rendered those bodies and experiences invisible in public life. Hence, knowledge, institutional cultures and identity development are some of the significant dimensions of the decolonial imperative. An epistemic rupture must be linked to a historical analysis of the daily experiences of those who are oppressed - and these can be told and performed through narratives and social action. As illustrated through the stories of the students who participated in this Photovoice project, alternative ways of knowing, thinking, and doing occur through creative acts of telling and resistance.

\section{SOLIDARITY, RESISTANCE, AND CHANGE}

These everyday experiences of students presented above create the conditions for isolation and despair but also possibilities for radical change. Working with students through Photovoice methods revealed how they made sense of their existence at UCT. The policing of their bodies and behaviours in residences, in bathrooms, and elsewhere on campus was intimately linked with their identities as black and LGBT students (Boonzaier and Mkhize 2017). However, through the spaces for discussion created by the project, they also revealed their agency and resistance:

"You know what, why must I carry on maintaining this system because this system hasn't been helping me. In fact, it's been repressing me if anything, and it's been violent towards myself, towards so many generations of just black people. What vested interest do I have in maintaining this structure?” (Samkelo).

A key strategy for resistance was the creation of spaces for belonging and solidarity. These happened through friendship groups or alliances with other groups who shared common experiences of alienation. Naledi describes how UCT provided her with a community of conscious young black women with whom she could relate to in the face of adversity: 


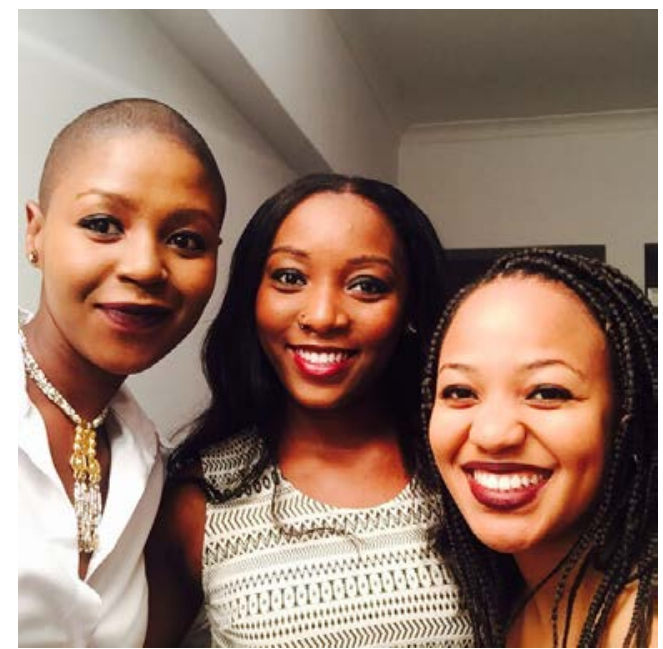

Photo 4: Brown girls

"UCT has also presented me with a group of conscious Brown girls. By this I mean that there are Black girls in UCT, found across all faculties, who are very much aware of the fact that black women often find themselves at the bottom of the feeding pyramid. We understand that it is difficult to be a black woman at work, at school, at home, in social spaces, etc. And despite that we try by all means to form a solidarity and support system.” (Naledi).

The RMF and Fees Must Fall (FMF) movements were also instrumental in creating spaces of belonging. Despite the divides that transpired within the latter phases of the movement, students also described the occupation of the administrative buildings as spaces where they found a sense of belonging by contrast to residence life. The student movement also created alliances and solidarity with workers:

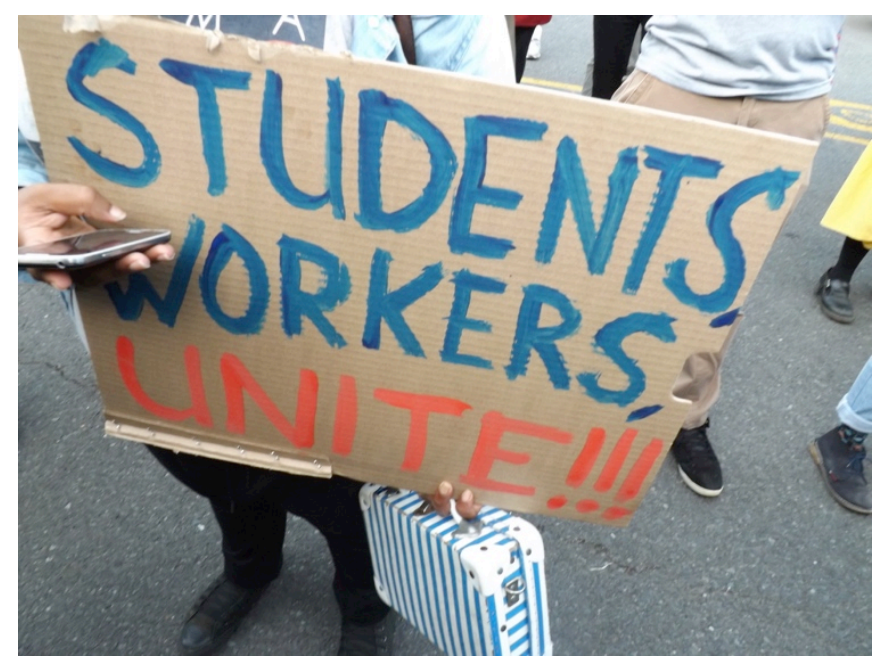

Photo 5: Silent Slaves

"Students protest in solidarity with the workers of UCT. To stop exploiting workers and towards earning a living wage and not a poverty one. \#EndOutsourcing\#Oct6\#Outsourced.” (Mandisa). 
By joining forces and aligning themselves with others, students built a broad-based movement that began to articulate the content of decolonization as anti-racist, anti-exploitative, and gender non-conforming.

In the final stage of the project, an exhibition was held at UCT, showcasing the photonarratives that the students produced. The exhibition was attended by many students and staff, including members of the university executive. This was an important source of recognition for the students, where not only were their voices heard, but where they felt they had access to high ranking members of the university community who they normally would not have access to. Numerous messages of support and invitations to present in different faculties subsequently followed extending the platform for their photo-narratives to be seen and heard. This phase of the project was an opportunity to raise awareness and sensitize others to the experiences of symbolic violence at UCT. Hence, the photovoice project in itself was a process of resistance and change in the sense that it got students to come together in solidarity around a narrative of resistance and to participate in practical activities to voice their struggles and build awareness of their circumstances and the institutional practices of exclusion.

\section{CONCLUSION}

Overall, the findings demonstrate how experiences of belonging and exclusion in academia play themselves out in everyday life. At stake is access to knowledge, power, and the resources for identity. Listening to students' experiences gives a lens into the complex and often invisible oppressions that happen in various spaces across the institution.

Students spoke about the violence of institutional spaces, in particular the policing of their bodies and the silencing of alternative ways of knowing and doing. By being recognized in this study as valuable contributors to academic spaces, they were able to articulate in powerful ways their affective experiences of alienation and the changes needed to enable a more inclusive environment. Of particular concern is the lack of attention given to the multiplicities of gendered identities and the need for the university to cater for the needs of all students.

Despite significant changes by previous generations and at great sacrifice, we have nevertheless inherited institutions that, in the main, still follow the same logic and rationale as they did under the previous regime, reproducing colonial forms of oppression and control. Universities in particular have been key sites for the production of intellectual and knowledge projects that served to institutionalize and legitimize colonial policies and practices (NdlovuGatsheni 2013; Mazrui 2005). Indeed, universities are alienating when they present only a version of reality based on western thought, to the exclusion of all other versions of reality. Our 
different understandings of reality are at the core of who we are, where we belong, and what we believe to be true. When dominant notions of science and knowledge are closely tied to certain perspectives, they serve to create an elitist group of insiders that are more likely to be recognized as equal or superior and more entitled to belong in academic spaces. What is needed is an interrogation of how the university can be instrumental in shifting power relations towards building a more just and egalitarian society, inside and outside its structures.

Creating sustainable conditions for a just society requires an epistemic shift: a change in attitudes of mind and an understanding of competing realities. The university must play a central role in this endeavor given its location at the interface between knowledge production and the daily lives of ordinary South Africans. Through alternative knowledges, intellectual argument, artistic and spiritual expressions and self-critique, people’s experiences, agency and ideas can renew the values and beliefs that should guide our society and institutions.

\section{NOTES}

1. Black in the context of this study referred to students who were classified under Apartheid as African, Coloured and Indian. However, the participants whose stories are presented in this article all happened to be of African descent.

2. Rhodes Must Fall (RMF) was a student movement that emerged at UCT in 2015 calling for the removal of the statue of Cecil John Rhodes from a central location on UCT Upper Campus. The movement was sparked by an incident involving a student protester throwing feces on the Rhodes statue. This was followed by a student occupation of the administrative buildings bringing the university to a standstill and resulting in the removal of the statue. The movement was successful in bringing attention to the symbolic violence of institutional practices at UCT and the need for radical change.

3. http://www.uct.ac.za/main/explore-uct/transformation

\section{REFERENCES}

Alexander, M. J. 2005. Pedagogies of crossing: Meditations of feminism, sexual politics, memory, and the sacred. Durham: Duke University Press.

Bilodeau, B. L. 2009. Genderism: Transgender students, binary systems and higher education. Saarbrücken, Germany: Verlag Dr. Müller.

Boonzaier, F. 2014 Talking against dominance. South African women resisting dominant discourse in narratives of violence. In Creating counter-stories: Women voicing resistance, ed. M. N. Lafrance and S. McKenzie-Mohr, 102-120. New-York: Routledge.

Boonzaier, F. and L. Mkhize. 2018. Bodies out of place: Black queer students negotiating identity at the University of Cape Town. South African Journal of Higher Education 32(3): 81-100.

Brydon-Miller, M. 1997. Participatory action research: Psychology and social change. Journal of Social Issues 35(4): 657-666.

Catalani, C. and M. Minkler. 2010. Photovoice: A review of the literature in health and public health. Health, Education and Behavior 37(3): 424-451.

Cloete, N. 2002. Policy expectations. In Transformation in higher education: Global pressures and local realities in South Africa, ed. N. Cloete, R. Fehnel, P. Maassen, T. Moja, H. Perold and T. Gibbon, 87-108. Cape Town: Juta. 
Cornell, J. and S. Kessi. 2016. Black students' experiences of transformation at a previously "white only" South African university: A photovoice study. Ethnic and Racial Studies. DOI: 10.1080/01419870.2016.1206586.

Crenshaw, K. 1994. Mapping the margins: Intersectionality, identity politics, and violence against women of color. In The public nature of private violence, ed. M. A. Fineman and R. Mykitiuk, 93-118. New-York: Routledge.

Collins, P. H. 2000 Black feminist thought: Knowledge, consciousness, and the politics of empowerment. $2^{\text {nd }}$ Edition. New-York: Routledge.

Davies, C. B. 2014. Pan-A fricanism, transnational black feminism and the limits of culturalist analyses in African gender discourses. Feminist Africa 19: 78-93.

Fanon, F. 1986. Black skin, white masks. London: Pluto Press (1952-French).

Freire, P. 1970. The pedagogy of the oppressed. London: Penguin.

Garvey, J. C. and S. R. Rankin. 2015. The influence of campus experiences on the level of outness among trans-spectrum and queer-spectrum students. Journal of Homosexuality 62: 374-393.

Gordon, L. 2015. Race and justice in higher education: Some global challenges with attention to the South African context. In Being at home: Race, institutional culture and transformation at South African higher education institutions, ed. P. Tabensky and S. Matthews, 157-183. Pietermaritzburg: UKZN Press.

Hall, S. 1990. Cultural identity and diaspora. In Identity, community, culture, difference, ed. J. Rutherford. London: Lawrence and Wishart.

Hames, M. 2007. Sexual identity and transformation at a South African university. Social Dynamics 33(1): 52-77.

Howarth, C. and E. Andreouli. 2017. The social psychology of everyday politics. London and NewYork: Routledge.

Hook, D. 2004. Fanon and the psychoanalysis of racism. In Critical psychology, ed. D. Hook, N. Mkhize, P. Kiguwa, A. Collins, E. Burman and I. Parker, 115-138. Cape Town: UCT Press.

Jones, M. 2012. "UCT unable to accept only top matriculants." Cape Times, 22 March. http://www.iol.co.za/capetimes/uct-unable-to-accept-only-top-matriculants-1261460 (Accessed 6 June 2017).

Kessi, S. and F. Boonzaier. 2017. Resistance and transformation in postcolonial contexts. In The social psychology of everyday politics, ed. C. Howarth and E. Andreouli, 116-130. London and NewYork: Routledge.

Kessi, S. and J. Cornell. 2015. Coming to UCT: Black students, transformation and discourses of race. Journal of Student Affairs in Africa 3(2): 1-16. DOI: 10.14426/jsaa.v3i2.132.

Lewis, D. 2011. Representing African sexualities. In African Sexualities, ed. S. Tamale, 199-216. Oxford: Tumibuka Press.

Maldonado-Torres, N. 2016. Outline of ten these on coloniality and decoloniality. Retrieved from Foundation Frantz Fanon: http://frantzfanonfoundation-fondationfrantzfanon.com/article 2360.html

Mama, A. 1997. Sheroes and villains: Conceptualizing colonial and contemporary violence against women in Africa. In Feminist genealogies, colonial legacies, democratic futures, ed. M. J. Alexander and C. T. Mohanty, 46-62. New-York and London: Routledge.

Matandela, M. 2015. Rhodes must fall: How black women claimed their place. Mail and Guardian, 30 March 2015. https://mg.co.za/article/2015-03-30-rhodes-must-fall-how-black-women-claimedtheir-place (Accessed 6 June 2017).

Matebeni, Z. 2015. Sexual minorities in South Africa. In International Encyclopedia of the Social and Behavioural Sciences, Volume 21, ed. J. D. Wright, 744-749. $2^{\text {nd }}$ Edition, Oxford: Elsevier.

Mazrui, A. 2005. Pan-africanism and the intellectuals. In African intellectuals: Rethinking politics, 
language, gender, and development, ed. T. Mkandawire, 56-77. Dakar: CODESRIA Books and London and New-York: Zed Books.

McKinney, J. S. 2005. On the margins: A study of the experiences of transgender college students. Journal of Gay and Lesbian Issues in Education 3(1): 63-75.

Mkhize, N., J. Bennet, V. Reddy and R. Moletsane. 2010. The country we want to live in: Hate crimes and homophobia in the lives of black lesbian South Africans. Pretoria: HSRC Press.

Msibi, T. 2013. Queering transformation in higher education. Perspectives in Education 31(2): 65-141.

Msibi, T. and V. Jagessar. 2015. Restricted freedom: Negotiating same-sex identifications in the residential spaces of a South African university. Higher Education Research and Development 34(4): 750-762.

Murray, M. 2000. Levels of narrative analysis in health psychology. Journal of Health Psychology 5(2): 337-347.

Mwikya, K. 2014. Unnatural and un-African: Contesting queer-phobia by Africa's political leadership. Feminist Africa 19: 98-105.

Ndlovu-Gatsheni, S. 2013. Decolonizing the university in Africa. The Thinker 51.

Ndebele, N. 2016. They are burning memory. University of Johannesburg. http://www.njabulondebele. co.za/2016/09/they-are-burning-memory/ (Accessed 17 September 2016).

Ratele, K. 2009. Apartheid, anti-apartheid and post-apartheid sexualities. In The prize and the price: Shaping sexualities in South Africa, ed. M. Steyn and M. van Zyl, 290-305. HSRC Press.

Rankin, S. R. 2003. Campus climate for gay, lesbian, bisexual, and transgender people: A national perspective. New York, NY: National Gay and Lesbian Task Force Policy Institute.

Read, B., L. Archer and C. Leathwood. 2003. Challenging cultures? Student conceptions of "belonging” and "isolation" at a post-1992 university. Studies in Higher Education 28(3): 261-277. DOI: $10.1080 / 03075070309290$.

Riessman, C. K. 2008. Narrative methods for the human sciences. Los Angeles: Sage Publications.

Said, E. 1993. Culture and imperialism. London: Vintage.

Seelman, K. L. 2014. Recommendations of transgender students, staff, and faculty in the USA for improving college campuses. Gender and Education 26(6): 618-635.

Sennett, J., G. Finchilescu, K. Gibson and R. Strauss. 2003. Adjustment of black students at historically white South African university. Educational Psychology 23(1): 107-116. DOI: 10.1080/01443410303219.

Soudien, C., W. Michaels, S. Mthembi-Mahanyele, N. Nkomo, G. Nyanda and N. Nyoka. 2008. Report of the Ministerial Committee on transformation and social cohesion and the elimination of discrimination in public higher education institutions. Pretoria: Department of Education.

Walker, M. 2005. Race is nowhere and race is everywhere: Narratives from black and white South African university students in post-apartheid South Africa. British Journal of Sociology of Education 26(1): 41-54. DOI: 10.1080/13613320500110501.

Wang, C. and M. A. Burris. 1997. Photovoice: Concept, methodology, and use for participatory needs assessment. Health Education \& Behavior 24(3): 369-387.

Woods, R. L. 2001. "Oh sorry, I'm a racist”: Black student experiences at the University of Witwatersrand. In Apartheid no more: Case studies of South African universities in the process of transformation, ed. R. O. Mabokela, K. L. King and R. F. Arnove, 91-110. Westport, CT: Bergin \& Garvey. 